\title{
Fostering Creativity in Creative Environments: An Empirical Study of Saudi Architectural Firms
}

\author{
Ahmed Rashad ElMelegy \\ The American University in Dubai \\ E-Mail: aelmelegy@aud.edu \\ Qadir Mohiuddin \\ New York Institute of Technology \\ E-Mail: qmohiudd@nyit.edu \\ Jess Boronico \\ New York Institute of Technology \\ E-Mail: jboronic@nyit.edu \\ Ahmed A. Maasher \\ IRAM Real Estate Development Co. \\ E-Mail: aamaasher@gmail.com
}

\begin{abstract}
Architecture, by its very nature is about creativity, not only in design but in all its forms, and therefore it is safe to assert that creativity and innovation are at the root of architectural design practices. This empirical research examines the factors that affect organizational creativity in architectural firms in Saudi Arabia in the context of Amabile's componential theory. The research sample consisted of 210 professionals from five architectural firms operating in the Kingdom of Saudi Arabia. Structural equation modeling was used to test the research hypotheses. The research findings suggest that management practices, which permit autonomy, risk-taking, rewards for creativity and innovation, have the greatest impact on organizational creativity, briefly defined as the creation of a valuable new product. Furthermore, it can be surmised that other elements of Amabile's componential theory including lack of organizational impediments, sufficient resources, realistic workload pressure, freedom, challenging work, management encouragement, and work group support have a significant impact on organizational creativity. The study also indicated that organizational encouragement
\end{abstract}


has no significant causal connection with organizational motivation and therefore organizational creativity. The results extend the knowledge and understanding of the factors that affect creativity in exclusively creative environments. In addition, the implications for managerial practices and executive decision-making are explored.

\section{Keywords: Organizational Creativity, Management Practices, Organizational Motivation, Amabile's Componential Theory, Kingdom of Saudi Arabia}

\section{INTRODUCTION}

Intense global competition is forcing the development of a culture that nurtures creativity. Conceptually, creativity is hard to define, and even when organizations succeed in innovation projects, managers are not always satisfied with the results (Fagerberg, Mowery, \& Nelson, 2006). What can be done, however, is to establish a culture and environment that fosters value-added services (Coveney, 2008; Kozbelt, Beghetto, \& Runco, 2010). In keeping with earlier realities of global competition, which certainly still hold true now, Amabile (1988, p. 126) asserted that creative employees have become the source of original and potentially useful ideas and solutions for a firm's renewal of products, services, and processes.

Organizational creativity is considered a new research area (Shalley, Gilson, \& Blum, 2009). The main focus of recent research on creativity has been on creative subprocesses in an operational sense (Rietzschel, De Dreu, \& Nijstad, 2009) where there is an obvious need for an integrative framework for creativity applications in open and continuously innovative workplaces (Scharmer, 2009). The ability to develop a culture that nurtures creativity is crucial and if it does not occur spontaneously, managers need to take responsibility to establish the right work environment, as well as to develop innovation strategies that foster new ideas to be transformed into value-added services (Coveney, 2008).

In the Kingdom of Saudi Arabia, construction and architectural design have experienced a significant boom in recent decades. This offers possibilities for researching the nexus between creativity, innovation and Saudi architectural firms' support for creativity. Thus, this paper examines the relationship between architectural design-related management practices and creativity in Saudi Arabia. The purpose of this study is to explore the factors affecting organizational creativity in five architectural firms operating in Saudi Arabia using Amabile's componential theory. The objective is to validate the hypotheses of this theory to help executives and decision makers in Saudi architectural firms to enhance their understanding of what makes their employees, and specifically designers, more creative and their organizations more innovative. 


\section{THEORETICAL CONTEXT AND RESEARCH HYPOTHESES}

\section{Creativity and Innovation in the Workplace}

Creativity is "the production of novel and useful ideas in any domain" (Amabile, Conti, Coon, Lazenby, \& Herron, 1996, p. 1155). Hennessey and Amabile (2010) stated that creativity is the production of a novel and appropriate response or solution to a problem. The response must be new, valuable, and fitting to a particular goal. The terms creativity and innovation are also often stated in tandem in practice although there are some variations in meaning (Hunter, Bedell, \& Mumford, 2007). The main distinction between the two is that creativity is the generation of creative ideas while innovation is the implementation of these ideas (Heye, 2006). The role of individual creativity in fostering organizational creativity and innovation is an essential ingredient for longterm success and survival (Amabile, Burnside, \& Gryskiewicz, 1999; Pitta, 2009).

Organizational creativity is defined as "the creation of a valuable, useful new product, service, idea, procedure, or process by individuals working together in a complex social system" (Woodman, Sawyer, \& Griffin, 1993, p. 293). Pitta (2009) proposed that one of the key drivers of organizational creativity is the strong support of individual creativity. Coelho, Augusto, and Lages (2011) emphasized the need for an organizational culture that supports individual creativity and innovation. Organizations which failed to foresee the importance of creativity activities have had higher failure rates because of their weakness in establishing a culture and climate that values new ideas. Fostering creativity in the organizational culture would promote innovation and increase competitiveness.

Validating these assertions, Ismail (2005) states that successful organizations should provide a bond between creativity and innovation in their management practices. Pablo, Campo, and Skerlavaj (2011) conclude that innovation and creativity are two of the most important words in business because of intense global competition which drives the need to examine the factors that enable creativity and innovation.

\section{Factors Affecting Organizational Creativity}

The relationship between individual and organizational creativity has been discussed in many studies. Research in psychology has focused on individuals and intra-individual factors; sociological research has focused more on macro issues concerning the influence of the environment on creativity, with a significant emphasis on innovation (Pirola-Merlo \& Mann, 2004).

A growing number of papers suggests that the complexity in relationships among variables involved in the organizational creativity process requires a multi-dimensional 
approach (Chambers, 1969; Haberland \& Dacin, 1992; Borghini, 2005; Hee Kim, 2006; Kurtzberg, 2005; Hansen, Lumpkin, \& Hills, 2011; Massaro, Bardy, \& Pitts, 2012; Loewenberger, 2013). Many researchers have examined the factors that affect organizational creativity but Amabile's "Componential Model of Organizational Creativity" remains the most popular and widely used (Coveney, 2008; Tseng \& Liu, , 2011; Castro, Gomes, \& de Sousa, 2012; Stuhlfaut \& Windels, 2012; Yeh-Yun Lin \& Liu, 2012; Yi, Hu, Plucker, \& McWilliams, 2013; Perry-Smith, 2014). According to the theory, domain-relevant knowledge, creativity-relevant skills and motivation are the three intra-individual factors influencing creativity (Amabile, 1988). The Componential Model also asserts that organizational motivation, resources, and management practices are the main characteristics of the work environment that affect organizational creativity via these three intra-individual components (Amabile et al., 1996). In addition, creative organizations should be flexible while controlling risk, and should provide freedom and support for individuals to search for innovation through learning and experimentation (DiLiello \& Houghton, 2008).

Isaksen, Lauer, Ekvall, and Britz (2001) observed how the work atmosphere in companies influenced employees" participation in the creation of a "Creative Climate". According to the findings of this research, nine dimensions of the organizational climate are essential to enhance creativity: challenge and involvement, freedom, trust/openness, playfulness/humor, conflict, idea support, debate and risk taking. All of these dimensions -- with the exception of conflict -- have been proven to positively influence creativity. These dimensions were reduced by Andriopolous (2001) who stated that the dimensions that enhance or obstruct creativity in the work environment can be classified under five organizational dimensions: organizational climate, organizational culture, organizational structure and systems, leadership style, and resources and skills. Amabile and Mueller (2008) proposed five conceptual constructs for creativity, namely: encouragement, autonomy or freedom, resources, pressures, and organizational impediments.

Hamlin and Sawyer (2007) asserted that the work environment almost certainly affects the creativity of individuals and groups, but maybe less directly and strongly than some of the other factors. Recent research on the effect of the work environment on creativity suggests some elements of the work environment that can motivate employees to be more creative. Among these are the presence of teamwork support that requires sharing and discussing ideas, and the presence of complex challenging tasks that require creative problem solving (Meusburger, 2009). Innovative solutions require full collaboration between work groups in order to make optimal use of their skills to deal with the uncertainties (Taggar, 2002). Furthermore, Zhou, Hirst, and Shipton 
(2012) found that leadership style and managerial encouragement spur employees to participate and share their ideas. Eisenberger and Shanock (2009) demonstrated that organizational motivation fosters creativity by establishing a link between novel behavior and reinforcement. This argument has been supported by several studies that proved that rewards offered for novel performance have encouraged creativity (Hunter et al., 2007; Eisenberger, Armeli, Rexwinkel, Lynch, \& Rhoades, 2001; Epstein, Kaminaka, Phan, \& Uda, 2013).

\section{Amabile's Componential Theory}

Amabile's componential theory has been recognized as the main theory of individual and organizational creativity and a foundation for several other creativity theories (Hunter et al., 2007). The theory has two premises. First, the highest levels of creativity found in historically significant scientific discoveries and inventions are a continuum from low ordinary levels of creativity found in everyday life. Second, there are degrees of creativity in the work of any single individual, even within one domain. The creativity of a person at any given point in time is a function of the creativity components operating at the time within and around that person (Hunter et al., 2007). The theory has also identified the factors that stifle creativity, such as subcultures where emerging ideas are viewed unfavorably, organizational politics and related issues, an emphasis on the status quo, a low-risk attitude among top management, and severe time pressure (Klijn \& Tomic, 2010).

The theory was extended later to encompass innovation without changing the basic model of individual creativity. The expanded theory proposed a parallel set of components for innovation which include resources in the task domain, skills in innovation management, and motivation to innovate. These components constitute the work environment impacting individuals and teams. In 1996, Amabile published a revised version of the original model of individual creativity which included a modification of the intrinsic motivation principle (Amabile et al., 1996). Amabile and Mueller (2008) published an additional modification of the theory to include affect as a determinant for organizational creativity.

According to the modified theory, both intrinsic and extrinsic factors influence creativity. The intrinsic factors include components within the individual such as domain-relevant skills, creativity-relevant processes, and task motivation, whereas the extrinsic factors include components outside the individual like the surrounding environment. The surrounding environment and the social environment in particular provide extrinsic motivators that can stimulate or impede intrinsic motivation and creativity (Hamlin \& Sawyer, 2007). 
In keeping with the intrinsic motivators, Spender and Strong (2010) suggested that most creative and innovative ideas come from the people and are not discovered in the lab late at night, or in isolation of the executive suite. This is a statement that is difficult to challenge, and although valid, it is at best tenuous because it is not the only strong standalone factor in the relationship between the intrinsic and extrinsic. There are indeed times when the individual has the gumption and support system to push creativity through the membranes of society or organizations. However, if the membranes are impenetrable or discouraging, then the individual's creativity dies, or never sees the light of day in that particular environment. Thus, the heart of Amabile's model is to measure the extrinsic factors and how conducive they are for the individual to be creative, which is the other end of the spectrum dealing with the extrinsic.

Culpepper (2010) claims that if a creative environment is an imperative, assessment is necessary to identify both a starting point and a destination. In line with that and using previous research that identified an interactionist construction of organizational creativity (e.g., Amabile, 1983; Amabile \& Gryskiewicz, 1989; Woodman et al., 1993), Amabile et al. (1996) developed the "Keys to Creativity and Innovation" to examine the creativity of individuals and groups within the workplace which is considered as the first and most highly respected assessment tool used to examine the organizational climate for creativity (Amabile et al., 1999). According to Culpepper (2010, p. 8), "the central theoretical concern in the construction of KEYS was a desire to measure the influence of work environment on organizational creativity, in other words, the influence of extrinsics". Culpepper (2010) confirms that authors referring to the KEYS measure (e.g., Amabile et al., 1999; Perry-Smith \& Shalley, 2003; Shalley, Zhou, \& Oldham, 2004) invoke it to discuss implications for individual creativity at work, or refer to its strengths in the context of the corporate climate (e.g., Unsworth, 2001; Adams, Bessant \& Phelps, 2006).

Amabile et al. (1999) confirmed the validity of KEYS because it independently and quantitatively measured individual perceptions of the work environment apart from the creative products made in that environment. Culpepper (2010) also affirmed Amabile's confirmatory factor analysis and demonstrated that KEYS could measure both technical and non-technical work. Moreover, Culpepper showed that perceptions of the work environment can be aggregated across different respondents in the same environment as proposed by Amabile et al. (1996). Moreover, Culpepper (2010) concluded that Amabile's study does indeed succeed as a test of criterion-related validity as defined by Carmines and Zeller (1979) because it demonstrates that KEYS meets the criterion of detecting the environment for creativity through the measured projects. 


\section{The Conceptual Model}

Researching creative potential using conceptual approaches towards problemsolving processes was initiated by Nielsen, Pickett, and Simonton (2008). Galenson (2004) identified two creative methods or styles: "conceptual" and "experimental", where the former corresponds to the generation of a new idea (a sort of "deductive" process) through "divergent thinking"; the latter is a new combination of existing items (an "inductive" process that relies on experience) through "convergent thinking". Nielsen et al. (2008, p. 132) assert that "Creative tasks are usually categorized as convergent or divergent, yet most creative problems contain elements of both". Therefore, on the whole, convergent tasks require a single correct response, whereas divergent tasks require producing many different correct answers (Runco, 2007).

Prior research has led to the development of several diverse measuring instruments to assess creativity. To reiterate, the best-known of these instruments is KEYS which is adapted here to assess the climate for creativity in architectural firms in Saudi Arabia. The description of the KEYS variables are as follows.

\section{- Organizational Motivation}

According to KEYS for creativity and innovation, motivational factors, both intrinsic and extrinsic, are considered the driving factors behind creativity (Collins \& Amabile, 1999). Organizational motivation is comprised of two dimensions, which are organizational encouragement and lack of organizational impediments. In addition, two more dimensions will be considered in this paper that affect organizational motivation: sufficient resources and realistic workload pressure.

\section{- Organizational Encouragement}

Organizational encouragement refers to organizational culture and strategies that encourage creativity and innovation (Amabile et al., 1996). Organizational encouragement also refers to management's willingness to take risks, interest in generating new ideas, and in the fair and supportive evaluation of ideas. Organizations should support, reward and recognize creative ideas and innovative problem solving techniques which promote innovativeness and creativity (Zhou, Shalley, Martocchio, \& Ferris, 2003). In addition, organizations should have a mechanism for developing and communicating new ideas. Pirola-Merlo and Mann (2004) found that organizational support and encouragement lead to creative outcomes. The same findings were supported by Hunter et al. (2007) who argued that organizational encouragement influences employees' intrinsic motivation, and thus enhances their creativity. 
- Lack of Organizational Impediments

Organizational impediments such as internal political problems, harsh criticism, destructive internal competition, avoidance of risk, and overemphasis on the status quo are obstacles to creativity (Amabile et al., 1996; Isaksen \& Akkermans, 2011). Recent research on creativity suggests that formal and rigid management structures obstruct organizational creativity (Shalley \& Gilson, 2004; Tseng \& Liu, 2011). Organizations should develop policies and procedures that overcome these impediments and inspire people to take risks, and create a psychologically safe climate that allow employees to believe that they will not be blamed or punished for breaking with the status quo (Edmondson, 1999).

\section{- Sufficient Resources}

Organizational resources have been proven to be one of the factors in determining organizational creativity (Galende \& de la Fuente, 2003). Sufficient resources, including time, material, budget, people and information, have a great impact on creativity (Amabile, 1998). Creative tasks require substantial resources for incubation. Therefore, organizations should ensure that their employees have the resources to support the creative process (Amabile et al., 1996; De Jonge, Spoor, Sonnentag, Dormann, \& van den Tooren, 2012).

According to Andriopoulos (2001), sufficient time is a critical resource for promoting creativity because it allows employees to think creatively, explore different perspectives, and play with ideas rather than stick to the more efficient traditional methods. Employees under time pressure are significantly less likely to engage in creative cognitive processing (Amabile, Hadley, \& Kramer, 2002). However, in a few cases, time pressure can increase a creative person's motivation (Amabile \& Kramer, 2007).

The budget is another important resource necessary for creativity. Organizations should allocate a budget above a "threshold of sufficiency" to support the creativity process. Otherwise, employees may spend their creativity on finding additional resources instead of being creative (Amabile, 1988). People and information are also important resources (Gong, Cheung, Wang, \& Huang, 2012). The development of creative ideas requires input and support from multiple individuals or groups within an organization to share information and knowledge needed for pursuing creative activities (Mumford, Feldman, Hein, \& Nagao, 2001). Information exchange in the workplace advances a trust relationship that provides psychological safety for creative endeavors. Proactive employees engaged in more information exchange built stronger trust 
relationships with supervisors and colleagues which, in turn, increased employee creativity.

- Realistic Workload Pressure

Realistic workload pressure is another factor that affects creativity (Amabile, 1988). Here, it is important to distinguish two distinct forms of pressure: excessive workload pressure and challenges. The first should have a negative influence because workload pressure does not allow time for creativity. High workload pressure will force employees to resort to simple and efficient strategies that are less creative (Mumford et al., 2010). In contrast, challenges should have a positive influence on creativity because they force employees to think in new ways and motivate employees with creative potential to be more creative (Byron, Khazanchi, \& Nazarian, 2010, Epstein et al., 2013).

- Management Practices

Management practices are central for organizational creativity (Amabile, 1988). Management practices can enhance creativity by encouraging openness to new ideas, permitting autonomy and risk taking, rewarding creativity and innovations, providing challenging environment, and building a feeling of self-efficacy (Epstein et al., 2013). Research on creativity and innovation suggests several management stimulants that affect creativity. These include freedom, challenging work, managerial encouragement, and work group support (Amabile, 1988).

\section{- Freedom}

Freedom is considered the most vital of stimulants to creativity through management practices (Amabile \& Gryskiewicz, 1989). Freedom is defined as being in control of one's own work, or in control of what to do and how to do it. Creativity requires non-routine environments that eliminate mental obstacles and encourage nonroutine thinking (Csikszentmihalyi, 1999). Employees should have a strong sense of autonomy and self-efficacy which leads to more active efforts and creative output. (Tierney \& Farmer, 2011). Thus, to enhance creativity, management should provide total freedom for employees by eliminating directional guidance, constraints, and criticism. In addition, management should support self-choice and encourage employees to explore new ideas (Isaksen et al., 2001). 
- Challenging work

Challenging work refers to "a sense of having to work hard on challenging tasks and important projects" (Amabile et al., 1996, p. 1166). According to Amabile and Kramer (2007), challenging work improves organizational creativity. Challenging work includes long-term goals and vision, and high levels of employee engagement, commitment, and motivation. Furthermore, challenging work through supportive supervision has been proven to enhance employees' intrinsic motivation and thus led to more positive and creative outcomes (Haas, 2006; Zhou et al., 2012). Loewenberger (2013) found that creativity-supporting work environments are more likely to introduce new ideas and products.

Thus, management should create challenging work environments by setting creativity goals, and use developmental feedback and innovative evaluations that promote employees' intrinsic motivation (Zhou et al., 2003).

- Managerial Encouragement

According to Amabile et al. (1996), managerial encouragement is a key determinant of organizational creativity. Managerial encouragement practices entail practical support of attempts to introduce new and improved ways of execution (Bessant \& Tidd, 2007), and recognition of innovative efforts and continuous greeting of new ideas to sustain individual passion within teams (Amabile, 1998). Managers should impose team dynamics and organizational maneuvering, exploit challenges and risk taking; encourage exploration of new ideas, acknowledge individual initiative, and provide constructive feedback to encourage individuals to identify new ways of working and improving their innovative performance (Shalley \& Gilson, 2004; Zhou, 2008; Hunter et al., 2007).

In addition, management encouragement includes setting clear organizational goals for high levels of organizational creativity (Amabile \& Gryskiewicz, 1989), and using creative strategies as a way of obtaining desired outcomes (Runco, 2007). This was supported by Amabile and Kramer (2007) who found that when clear and effective goals were provided in a timely fashion, motivation increased. Moreover, role modeling by supervisors is more likely to also enhance creativity (Gong et al., 2012).

\section{- Work Group Support}

Work group support reflects the social aspects of work groups. Perceived workgroup support was proven to enhance creativity (Amabile et al., 1996). Hennessey and Amabile (2010) assert that "most creative work that gets done in organizations is accomplished by two or more individuals working closely together". Support from 
coworkers generally enhances individual creative self-efficacy, and increases the extent to which individuals identify their creative role within the workplace (Tierney \& Farmer, 2011). Farmer, Tierney, and Kung-McIntyre (2003) argued that when employees perceive that their coworkers have an expectation of creativity, they are more likely to engage in creative behaviors. Moreover, Lin and Liu (2012) found that the mere presence of creative coworkers enhances individual creativity.

Thus, management practices should promote work-group support by forming diverse groups that are open to new ideas, constructively challenge one another, communicate and provide feedback, manage conflict and trust, and help each other (Amabile et al., 1996; Diliello et al., 2011).

\section{The Research Hypotheses}

This study establishes the feasibility of the KEYS instrument in an architecture design environment in the Kingdom of Saudi Arabia. The conceptual model (Figure 1) is based on a modified version of the KEYS instrument. These measures form the basis of the following 10 hypotheses examined in this study.

$\mathrm{H}_{1}$ : Organizational encouragement has a significant positive effect on creativity moderated by organizational motivation in architectural firms in Saudi Arabia.

$\mathrm{H}_{2}$ : Lack of organizational impediments has a significant positive effect on creativity moderated by organizational motivation in architectural firms in Saudi Arabia.

$\mathrm{H}_{3}$ : Sufficient resources has a significant positive effect on creativity moderated by organizational motivation in architectural firms in Saudi Arabia"

$\mathrm{H}_{4}$ : Realistic workload pressure has a significant positive effect on creativity moderated by organizational motivation in architectural firms in Saudi Arabia"

$\mathrm{H}_{5}$ : Freedom has a positive effect on creativity moderated by management practices in architectural firms in Saudi Arabia

$\mathrm{H}_{6}$ : Challenging work has a significant positive effect on creativity moderated by management practices in architectural firms in Saudi Arabia

$\mathrm{H}_{7}$ : Management encouragement has a significant positive effect on creativity moderated by management practices in architectural firms in Saudi Arabia

$\mathrm{H}_{8}$ : Work group support has a significant positive effect on creativity moderated by management practices in architectural firms in Saudi Arabia

$\mathrm{H}_{9}$ : Organizational motivation has a significant positive effect on organizational creativity in architectural firms in Saudi Arabia 
$\mathrm{H}_{10}$ : Management practices has a significant positive effect on organizational creativity in architectural firms in Saudi Arabia

\section{RESEARCH METHODOLOGY}

\section{Sampling and Procedure}

For the purpose of this research, a stratified random sample of 241 architecture professionals from five private architectural firms operating in Saudi Arabia was used. Consideration was given to demographic factors such as gender, nationality, position, and education background of participants during the selection. Support staff including administration, support services and construction site supervisors were not considered in the sampling process as the research focus is on creativity in architectural firms, not organizational creativity in general.

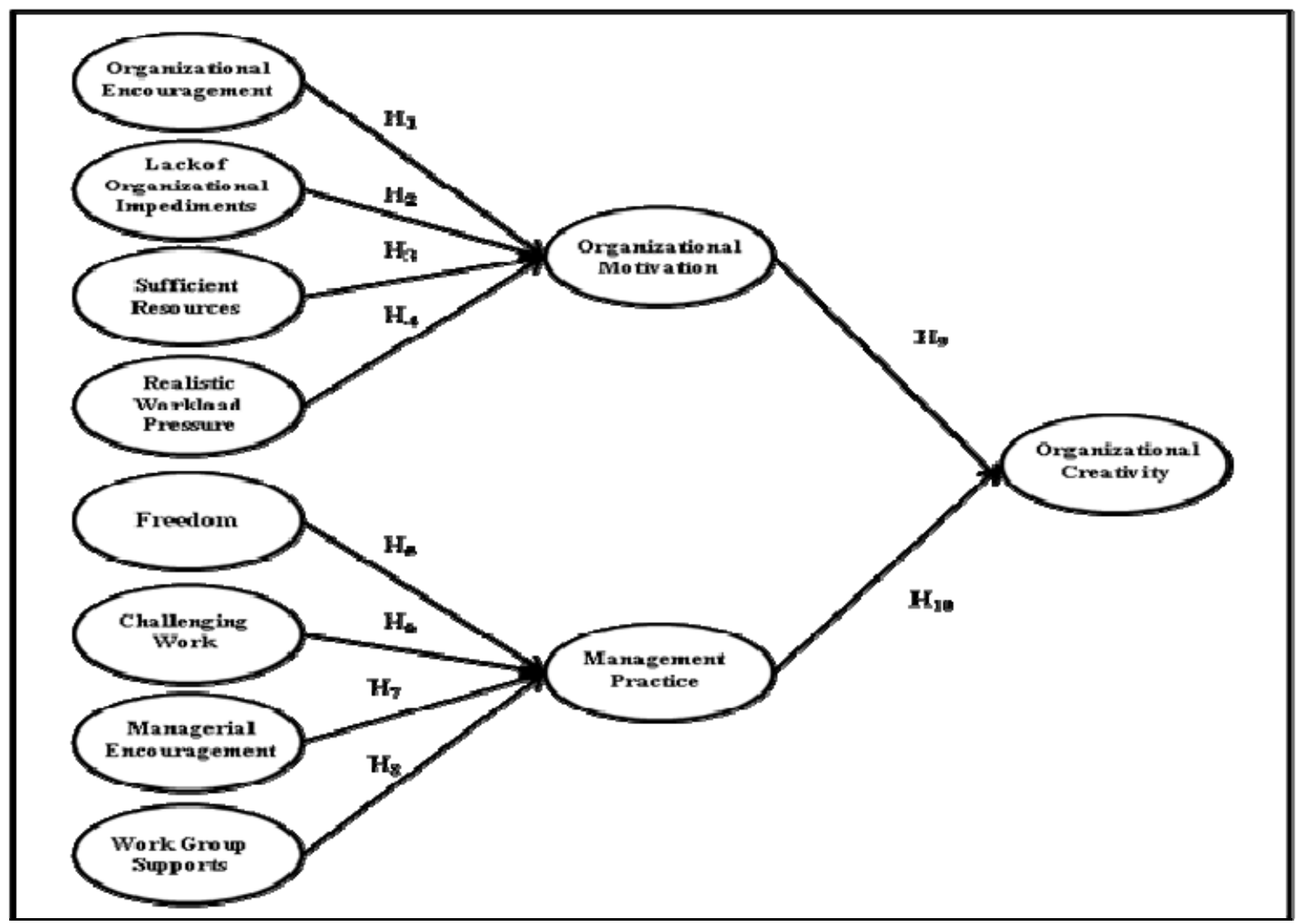

Figure 1 The Conceptual Model

A total of 241 questionnaires were distributed from February 2014 to April 2014, both by email and in person allowing respondents to complete it in their own time and in privacy. Out of 241 questionnaires distributed, 18 were partially incomplete, and 13 were returned blank or not returned at all. Accordingly, 210 questionnaires were 
considered to be valid for the purpose of this study. The sample size ranged from $23 \%$ to $64 \%$ of the total specialized staff in each firm as shown in Table 1. Gefen, Straub, and Boudreau (2000) stated that the minimum sample size for a path analysis should be greater than the larger of 10 times the number of items of the most complex construct in the model, or 10 times the largest number of independent constructs influencing the dependent variable. In this study, the number of items of the most complex is four, while the maximum number of independent variables impacting a dependent variable is four which confirms that our sample size is sufficient for this study.

Table 1 Profile of Participating Firms

\begin{tabular}{llcccc}
\hline Firm & Location & $\begin{array}{c}\text { Total } \\
\text { Number of } \\
\text { Staff }\end{array}$ & $\begin{array}{c}\text { Number of } \\
\text { Specialized } \\
\text { Staff }\end{array}$ & $\begin{array}{c}\text { Sample } \\
\text { Size }\end{array}$ & $\begin{array}{c}\text { Sample } \\
\text { Percentage* }\end{array}$ \\
\hline A & Jeddah, Riyadh & 311 & 126 & 51 & $40 \%$ \\
\hline B & Jeddah, Riyadh, Dammam & 846 & 212 & 49 & $23 \%$ \\
\hline C & Jeddah, Dammam & 702 & 171 & 47 & $27 \%$ \\
\hline D & Riyadh, Dammam & 124 & 65 & 35 & $54 \%$ \\
\hline E & Riyadh & 68 & 44 & 28 & $64 \%$ \\
\hline & Total & 2051 & 618 & 210 & $34 \%$ \\
\hline
\end{tabular}

Note: *Sample size as a percentage from the specialized staff

\section{Questionnaire Development}

The questionnaire used in this research is based on a thorough review of the organizational creativity literature. The research model assumes that organizational creativity is influenced by organizational motivation and management practices which are, in turn, affected by another set of independent variables as shown in Figure 1. The questionnaire consisted of 42 questions on a 5-point Likert-type scale ( $1=$ strongly disagree to $5=$ strongly agree). The questionnaire was designed in English with the assumption that all respondents understand English because of their educational background. The number of items used in this study has been reduced from the number in the original KEYS questionnaire.

\section{Instrument Validity and Reliability}

Content validity ensures that construct items are representative (Cronbach, 1971). In this research, the construct items were developed based on Amabile's KEYS "Assessing the Climate for Creativity" which have been shown to exhibit strong content validity. Although its factor structure has been questioned when tested by external researchers, since many statements referred to more than one factor (Mathisen \& 
Einarsen, 2004), it still offers a solid starting point for the assessment of organizational creativity in architectural design-based environments.

Reliability and validity refer to the degree to which an instrument measures what it purports to be measuring (Cronbach \& Meehl, 1955). Convergent validity ensures that the measures of each construct are highly correlated while discriminant validity ensures that there is a low correlation between the measures of different constructs (Gefen et al., 2000). According to Fornell and Larcker (1981), to assess the convergent validity of a questionnaire, researchers have to examine the factor loading of each item, the average variance extracted (AVE) of each construct, and the reliability of each construct. As a rule of thumb, the factor loading of each item should load above 0.5 and must be significant; the average variance extracted (AVE) of each construct should be more than 0.5 ; whereas the value of the construct reliability of each construct should be greater than 0.7 (Nunnally \& Bernstein, 1994).

Confirmatory factor analysis was performed to assess the reliability of each item (Gefen and Straub, 2000). From the original 42 items, four were excluded (LOI1, CW4, WGS1, and OM3) due to low loadings and two items were eliminated (ME4, and OC4) due to insignificance. The factor loadings for the remaining items were above 0.5 as shown in Table 2. In addition, construct reliability values ranged from 0.774 to 0.881 and all AVEs were above 0.5. Thus, the results of the convergent validity test indicate that the instrument used has acceptable convergent validity based on the measures proposed by Nunnally and Bernstein (1994).

According to Fornell and Larcker (1981), discriminant validity is assessed by comparing the average variance (AVE) shared by items within a construct with the square of the inter-construct correlations. The results of the discriminant validity test (Table 3) confirm that the instrument used has acceptable discriminant validity.

\section{Data Analysis}

Descriptive statistics were used to analyze the sample demographics using IBM SPSS Statistics 19. Structural equation modeling was utilized to assess the validity of the path analysis and the proposed hypotheses using AMOS 19.0 software. Confirmatory factor analysis (CFA) was conducted to assess the overall fit of the measurement model and the structural model (SEM) was tested to examine the proposed hypotheses. 


\section{DATA ANALYSIS AND RESULTS}

\section{Sample Profile}

The demographic profile of respondents is summarized in Table 4. The typical respondent was an Arab male architect who had a bachelor's degree, with 6 to 10 years of total work experience, and less than five years in a senior position in his company. Sample demographics were consistent with characteristics of the labor market in the Architectural field in GCC (Gulf Cooperation Council countries of Saudi Arabia, Bahrain, Kuwait, UAE, Oman and Qatar), where the majority were males holding a bachelor's degree, and were mid-career English literate Arab expatriates. In Saudi Arabia and in many GCC countries most workers in the construction field are Arabs and Asians.

An analysis of the nationality shows consistent results among the sample. Arabs and Asians constitute a majority of the labor force in construction and in the design consultation field in Saudi Arabia, as well as in most of the GCC countries. However, an increasing number of Saudi professionals have become visible in most Saudi service sectors due to the Saudization law. It should also be noted that a significant percentage of Westerners are noticeable not just in international companies practicing in Saudi Arabia, but also in many of the local firms.

\section{Model Fit}

The values of fit indices shown in Table 5 indicate a good fit of the structured model to the data collected based on the benchmark values suggested by Byrne. (2013). All the measures were above the benchmark values except for CMIN/DF, AGFI and RMSEA which is likely due to the effect of sample size.

\section{Hypotheses Testing Results}

Structural equation modeling (SEM) was used to test the proposed hypotheses. The maximum likelihood method was chosen since it supports both exploratory and confirmatory research (Gefen et al., 2000), and can be applied to relatively small sample sizes (Fornell \& Larcker, 1981).

For the overall model shown in Figure 2, all path coefficients of the hypothesized model were significant at $\mathrm{p}<0.05$ level except for the effect of Organizational Encouragement on Organizational Motivation. Thus, hypothesis $\mathrm{H}_{1}$ was rejected whereas hypotheses $\mathrm{H}_{2}$ through $\mathrm{H}_{10}$ were supported. Approximately $89 \%$ of the variance in Organizational Creativity $\left(\mathrm{R}^{2}=0.891\right)$ is accounted for by the variables in the model. The values of coefficient of determination $\left(\mathrm{R}^{2}\right)$ for the endogenous constructs Management Practices $\left(\mathrm{R}^{2}=0.384\right)$, and Organizational Motivation $\left(\mathrm{R}^{2}=\right.$ 
0.578 ) exceeded the $10 \%$ benchmark recommended by Falk and Miller (1992). A high $\mathrm{R}^{2}$ obtained here suggests a good application of the model tested in this research.

Table 2 Convegent Validity Test Results

\begin{tabular}{|c|c|c|c|c|c|c|}
\hline Construct & Measurement & Factor & p-Value & Item & AVE & Cronbach \\
\hline & OE1 & 0.704 & $<0.001$ & 0.495 & 0.512 & 0.807 \\
\hline Organizational & OE2 & 0.696 & $<0.001$ & 0.484 & & \\
\hline \multirow{2}{*}{ Encouragement } & OE3 & 0.767 & $<0.001$ & 0.589 & & \\
\hline & OE4 & 0.694 & $<0.001$ & 0.481 & & \\
\hline \multirow{4}{*}{$\begin{array}{l}\text { Lack of } \\
\text { Organizational } \\
\text { Impediments }\end{array}$} & LOI1* & 0.091 & 0.042 & 0.008 & 0.611 & 0.823 \\
\hline & LOI2 & 0.847 & $<0.001$ & 0.717 & & \\
\hline & LOI3 & 0.638 & $<0.001$ & 0.407 & & \\
\hline & LOI4 & 0.842 & $<0.001$ & 0.710 & & \\
\hline \multirow{3}{*}{$\begin{array}{l}\text { Sufficient } \\
\text { Resources }\end{array}$} & SR1 & 0.775 & $<0.001$ & 0.600 & 0.634 & 0.839 \\
\hline & SR2 & 0.773 & $<0.001$ & 0.597 & & \\
\hline & SR3 & 0.840 & $<0.001$ & 0.706 & & \\
\hline \multirow{4}{*}{$\begin{array}{l}\text { Realistic } \\
\text { Workload } \\
\text { Pressure }\end{array}$} & RWP1 & 0.891 & $<0.001$ & 0.793 & 0.578 & 0.844 \\
\hline & RWP2 & 0.767 & $<0.001$ & 0.589 & & \\
\hline & RWP3 & 0.662 & $<0.001$ & 0.438 & & \\
\hline & RWP4 & 0.702 & $<0.001$ & 0.492 & & \\
\hline \multirow{3}{*}{ Freedom } & FR1 & 0.606 & $<0.001$ & 0.367 & 0.603 & 0.813 \\
\hline & FR2 & 0.668 & $<0.001$ & 0.446 & & \\
\hline & FR3 & 0.998 & $<0.001$ & 0.997 & & \\
\hline \multirow{4}{*}{$\begin{array}{l}\text { Challenging } \\
\text { Work }\end{array}$} & CW1 & 0.667 & $<0.001$ & 0.445 & 0.605 & 0.814 \\
\hline & CW2 & 0.999 & $<0.001$ & 0.998 & & \\
\hline & CW3 & 0.611 & $<0.001$ & 0.373 & & \\
\hline & CW4* & 0.479 & $<0.001$ & 0.230 & & \\
\hline \multirow{4}{*}{$\begin{array}{l}\text { Managerial } \\
\text { Encouragement }\end{array}$} & ME1 & 0.658 & $<0.001$ & 0.433 & 0.618 & 0.826 \\
\hline & ME2 & 0.754 & $<0.001$ & 0.568 & & \\
\hline & ME3 & 0.923 & $<0.001$ & 0.852 & & \\
\hline & ME4** & 0.517 & 0.220 & 0.267 & & \\
\hline \multirow{4}{*}{$\begin{array}{l}\text { Work Group } \\
\text { Support }\end{array}$} & WGS1* & 0.147 & 0.068 & 0.022 & 0.712 & 0.881 \\
\hline & WGS2 & 0.859 & $<0.001$ & 0.738 & & \\
\hline & WGS3 & 0.787 & $<0.001$ & 0.619 & & \\
\hline & WGS4 & 0.882 & $<0.001$ & 0.777 & & \\
\hline \multirow{4}{*}{$\begin{array}{l}\text { Organizational } \\
\text { Motivation }\end{array}$} & OM1 & 0.862 & $<0.001$ & 0.744 & 0.642 & 0.842 \\
\hline & OM2 & 0.711 & $<0.001$ & 0.505 & & \\
\hline & OM3* & 0.009 & 0.315 & 0.000 & & \\
\hline & OM4 & 0.822 & $<0.001$ & 0.676 & & \\
\hline \multirow{4}{*}{$\begin{array}{l}\text { Management } \\
\text { Practices }\end{array}$} & MP1 & 0.949 & $<0.001$ & 0.901 & 0.518 & 0.805 \\
\hline & MP2 & 0.640 & $<0.001$ & 0.409 & & \\
\hline & MP3 & 0.631 & $<0.001$ & 0.398 & & \\
\hline & MP4 & 0.603 & $<0.001$ & 0.363 & & \\
\hline \multirow{4}{*}{$\begin{array}{l}\text { Organizational } \\
\text { Creativity }\end{array}$} & OC1 & 0.94 & $<0.001$ & 0.887 & 0.545 & 0.774 \\
\hline & OC2 & 0.562 & $<0.001$ & 0.316 & & \\
\hline & OC3 & 0.657 & $<0.001$ & 0.432 & & \\
\hline & $\mathrm{OC} 4 * *$ & 0.534 & 0.290 & 0.285 & & \\
\hline
\end{tabular}

*Item excluded due to low loading (factor loading $<0.5$ )

**Item excluded due to insignificance ( $p$-value $>0.05$ ) 
Table 3 Discriminant Validity Test Results*

\begin{tabular}{llllllllllll}
\hline & OE & LOI & SR & RWP & FR & CW & ME & WGS & OM & MP & OC \\
\hline OE & $\mathbf{0 . 5 1 2}$ & & & & & & & & & & \\
LOI & 0.286 & $\mathbf{0 . 6 1 1}$ & & & & & & & & & \\
SR & 0.157 & 0.031 & $\mathbf{0 . 6 3 4}$ & & & & & & & & \\
RWP & 0.120 & 0.001 & 0.208 & $\mathbf{0 . 5 7 8}$ & & & & & & \\
FR & 0.025 & 0.015 & 0.059 & 0.032 & $\mathbf{0 . 6 0 3}$ & & & & & & \\
CW & 0.013 & 0.002 & 0.004 & 0.055 & 0.047 & $\mathbf{0 . 6 0 5}$ & & & & & \\
ME & 0.118 & 0.005 & 0.205 & 0.616 & 0.119 & 0.102 & $\mathbf{0 . 6 1 8}$ & & & & \\
WGS & 0.005 & 0.054 & 0.010 & 0.052 & 0.000 & 0.253 & 0.106 & $\mathbf{0 . 7 1 2}$ & & & \\
OM & 0.074 & 0.014 & 0.449 & 0.296 & 0.118 & 0.077 & 0.449 & 0.031 & $\mathbf{0 . 6 4 2}$ & & \\
MP & 0.025 & 0.030 & 0.039 & 0.039 & 0.888 & 0.009 & 0.157 & 0.008 & 0.142 & $\mathbf{0 . 5 1 8}$ & \\
OC & 0.008 & 0.000 & 0.011 & 0.059 & 0.034 & 0.894 & 0.100 & 0.219 & 0.098 & 0.005 & $\mathbf{0 . 5 4 5}$ \\
\hline
\end{tabular}

* Diagonal values in bold represent the AVEs while the off-diagonal values represent the squared inter-construct correlations.

The results show that lack of organizational impediments, sufficient resources and realistic work pressure have a positive and significant impact on organizational motivation. The effect of organizational encouragement on organizational motivation was not significant. Freedom, challenging work, management encouragement, and work group support have a significant direct impact on management practices. Finally, organizational motivation and management practices have a significant positive impact on organizational creativity. Table 6 provides the standardized beta coefficients and the t-values for the different hypotheses. 
Table 4 Demographic Profile of Respondents

\begin{tabular}{|c|c|c|c|}
\hline Demographic & Characteristic & Frequency & Percentage \\
\hline \multirow{2}{*}{ Gender } & Male & 134 & 63.8 \\
\hline & Female & 76 & 36.2 \\
\hline \multirow{5}{*}{ Nationality } & Saudi & 29 & 13.8 \\
\hline & Arab Not Saudi & 59 & 28.1 \\
\hline & Asian & 54 & 25.7 \\
\hline & Western & 41 & 19.5 \\
\hline & Multiple & 27 & 12.9 \\
\hline \multirow{3}{*}{ Education } & Bachelor Degree & 133 & 63.3 \\
\hline & Masters Degree & 52 & 24.8 \\
\hline & PhD. Degree & 25 & 11.9 \\
\hline \multirow{4}{*}{ Position } & Junior & 65 & 31 \\
\hline & Senior & 68 & 32.4 \\
\hline & Team Leader & 50 & 23.8 \\
\hline & Unit Manager & 27 & 12.9 \\
\hline \multirow{5}{*}{ Work Experience } & $<5$ Years & 26 & 12.4 \\
\hline & 6 - 10 Years & 62 & 29.5 \\
\hline & $11-15$ Years & 59 & 28.1 \\
\hline & $16-20$ Years & 38 & 18.1 \\
\hline & $21+$ Years & 25 & 11.9 \\
\hline \multirow{5}{*}{$\begin{array}{l}\text { Duration Within the } \\
\text { Company }\end{array}$} & $<5$ Years & 94 & 44.8 \\
\hline & $6-10$ Years & 82 & 39 \\
\hline & $11-15$ Years & 25 & 11.9 \\
\hline & $16-20$ Years & 8 & 3.8 \\
\hline & $21+$ Years & 1 & 0.5 \\
\hline \multirow{5}{*}{ Specialization } & Architect & 113 & 53.8 \\
\hline & Urban Planner & 31 & 14.8 \\
\hline & Designer & 26 & 12.4 \\
\hline & Civil Engineer & 25 & 11.9 \\
\hline & MEP Engineer & 15 & 7.1 \\
\hline
\end{tabular}


Table 5 Model Fit Summary

\begin{tabular}{llc}
\hline \multicolumn{1}{c}{ Fit Indices } & \multicolumn{1}{c}{ Benchmark } & Value \\
\hline CMIN $(\chi 2)$ & & 73.31 \\
DF & & 17 \\
CMIN/DF & less than 4 & 4.31 \\
CFI & greater than 0.93 & 0.97 \\
GFI & greater than 0.9 & 0.94 \\
AGFI & greater than 0.9 & 0.78 \\
RMSEA & less than 0.08 & 0.12 \\
TLI & greater than 0.9 & 0.90 \\
IFI & greater than 0.9 & 0.97 \\
NFI & greater than 0.9 & 0.96 \\
Holter $(0.05)$ & greater than 75 & 79 \\
Holter $(0.01)$ & greater than 75 & 96 \\
\hline
\end{tabular}

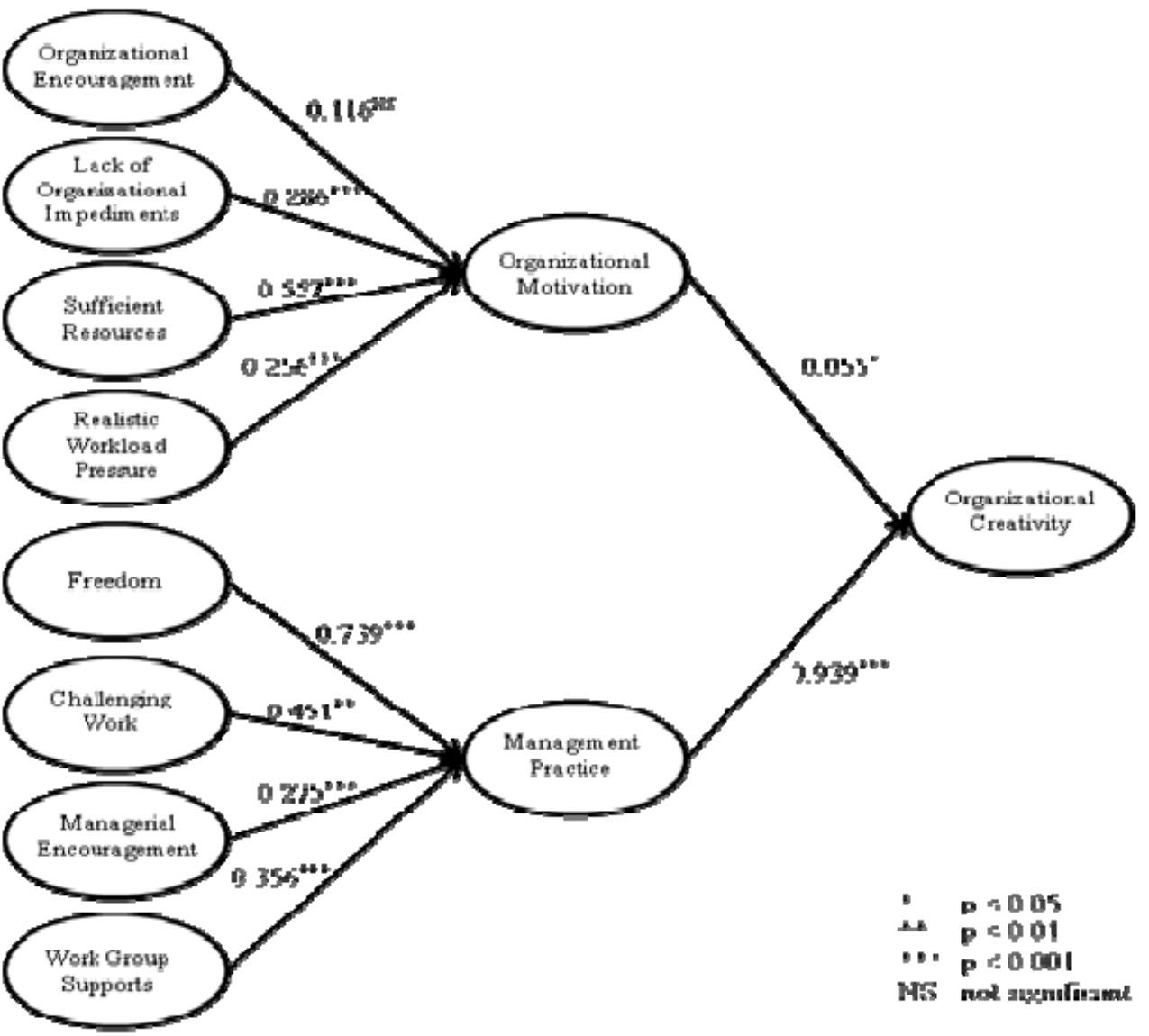

Figure 2 Results of the Path Analysis 
Table 6 The Results of the Hypotheses Testing

\begin{tabular}{lllll}
\hline Hypothesis & Causal Path & $\begin{array}{l}\text { Path } \\
\text { Coefficient }\end{array}$ & $t$-Value & Supported \\
\hline $\mathrm{H}_{1}$ & $\mathrm{OM} \leftarrow \mathrm{OE}$ & 0.116 & $1.951^{\mathrm{NS}}$ & $\mathrm{No}$ \\
$\mathrm{H}_{2}$ & $\mathrm{OM} \leftarrow \mathrm{LOI}$ & 0.286 & $5.261^{* * *}$ & Yes \\
$\mathrm{H}_{3}$ & $\mathrm{OM} \leftarrow \mathrm{SR}$ & 0.557 & $10.575^{* * *}$ & Yes \\
$\mathrm{H}_{4}$ & $\mathrm{OM} \leftarrow \mathrm{RWP}$ & 0.256 & $4.869^{* * *}$ & Yes \\
$\mathrm{H}_{5}$ & $\mathrm{MP} \leftarrow \mathrm{FR}$ & 0.739 & $4.325^{* * *}$ & Yes \\
$\mathrm{H}_{6}$ & $\mathrm{MP} \leftarrow \mathrm{CW}$ & 0.461 & $2.666^{* *}$ & Yes \\
$\mathrm{H}_{7}$ & $\mathrm{MP} \leftarrow \mathrm{ME}$ & 0.275 & $4.409^{* * *}$ & Yes \\
$\mathrm{H}_{8}$ & $\mathrm{MP} \leftarrow \mathrm{WGS}$ & 0.356 & $5.911^{* * *}$ & Yes \\
$\mathrm{H}_{9}$ & $\mathrm{OC} \leftarrow \mathrm{OM}$ & 0.055 & $2.458^{* *}$ & Yes \\
$\mathrm{H}_{10}$ & $\mathrm{OC} \leftarrow \mathrm{MP}$ & 0.939 & $41.583^{* * *}$ & Yes \\
\hline significant at .05 level; ** significant at .01 level & & \\
$* * *$ significant at .001 level; ; ${ }^{N S}$ not significant & &
\end{tabular}

\section{DISCUSSION AND CONCLUSION}

\section{Discussion}

Despite the importance of the concept of creativity and its effect on organizational success, prior research has provided no sound empirical support to evaluate the factors that affect creativity in creative environments. In order to fill this research gap, his study was conducted to examine which factors affect organizational creativity in architectural design firms in Saudi Arabia in terms of Amabile's componential theory of organizational creativity. The measurement instrument was developed based upon her KEYS tool of organizational creativity. The sample studied included a mixture of 210 designers and managers from five architectural design firms in Saudi Arabia to provide balanced opinions about their views of creativity within their organizations.

The results of the path analysis provided additional details about the impact and significance of each of the independent variables on the dependent variable. The results indicate that organizational motivation factors such as lack of organizational impediments, sufficient resources and realistic work pressure have a significant positive impact on organizational creativity. This is evident in the architecture design environment where the organization culture plays an important role in supporting and motivating creativity. Maintaining a balanced work environment that is demanding yet supportive, reducing barriers to creativity, limiting political problems and excessive criticism of new ideas, and setting clear objectives for projects are all necessary factors for creativity to flourish. Curiously, the effect of organizational encouragement on 
organizational motivation was not significant, which means organizational culture and strategies that encourage creativity and innovation, as well as management's willingness to take risks, interest in generating new ideas, along with fair and supportive evaluation of ideas did not hold much relevance.

Results also show that management practices in Saudi Arabia's architectural firms were directly impacted by four factors: freedom, challenging work, management encouragement, and work support. Amabile defined freedom as being in control of one's own work, and in control of what to do and how to do it. Csikszentmihalyi asserts that creativity requires non-routine environments that eliminate mental obstacles and encourage non-routine thinking. Challenging work was described by Amabile and Kramer (2007) as having a positive impact on organizational creativity, includes long term goals and vision, as well as, high levels of employee engagement, commitment, and motivation. Management encouragement, was posited by Amabile as a key determinant of organizational creativity. Work group support, according to Amabile, reflected social aspects, and was proven by other studies to enhance creativity. All four factors have a strong impact on organizational motivation and thus organizational creativity. These findings reinforce the reality in the challenging architecture design environment where designers often have the freedom to generate novel ideas and designs. The development of these novel ideas and designs are usually moderated, guided, and constructively evaluated by managers through assessment feedback to improve and adapt them within different projects. In addition, the architectural design environment depends on teamwork and the use of homogenous work groups that are synergistic and combine diverse talents to support and challenge each other.

The results of this study are in general consistent with the assumptions of the original componential theory (Amabile, 1988; Amabile et al., 1996) which indicate that organizational motivation and management practices are the most influential factors affecting creativity in organizations. In addition, the findings are in line with the empirical literature on creativity which demonstrates the moderating effect of freedom, management encouragement, lack of organizational impediments, sufficient resources, workgroup support, and realistic work pressure on creative potential and organizational creativity (Amabile et al., 1996; ; Zhou et al., 2003; Shalley et al., 2004; DiLiello \& Houghton, 2008; Tierney \& Farmer, 2011; Tseng \& Liu, 2011). These contextual factors were found to be effective predictors of creative potential in highly competitive environments (Hunter et al., 2007). 


\section{Implications for Theory and Practice}

This research has several theoretical and practical implications. While it contributes to the body of knowledge in the field of creativity, it also empirically evaluates the factors that affect organizational creativity in highly creative work environments. The research explores how to nurture creativity in the architectural design environment. It also validates the applicability of the KEYS tool for quantitatively measuring organizational creativity. Thus, the findings confirm that the tool can be used as a platform for empirically assessing the perceived work environment for creativity in the future.

It is essential that managers and decision makers in architectural design firms understand the relationship between creativity components and the work environment, and how they interact to enhance creativity. In line with this assertion, the study suggests several ways to boost creativity and innovation in their work environment. Architecture firms should set clear goals for projects, challenge their employees, give them as much autonomy as possible, and put the right people in the right place to enhance employees' intrinsic motivation. In addition, top management and executives should serve as advocates for creative projects in the organization and provide encouragement and support for creative work, for instance by reducing organizational impediments, lightening the workload on creative employees, providing sufficient resources for projects, and establishing well-coordinated mechanisms for recognizing and rewarding creative efforts.

This study has examined the factors affecting creativity as perceived by employees which might not necessarily be those that are perceived by their managers. The implication here for managers is that what is creative in their eyes might be quite different from what employees perceive it to be. Therefore, managers should consistently assess employees' creativity through research, interviews and group discussions in order to increase creativity in their work environment. Additionally, the results prove that maintaining creativity at work depends quite significantly on management practices. Managers who learn these lessons will recruit people who already have that spark of passion for their work as well as the requisite skills and experience, and kindle that spark by creating a work environment that lowers the obstacles and fosters the stimulants of creativity. Only then will their organizations be poised to lead through innovation.

Finally, this research study provides significant implications for Saudi architectural firms on how to develop additional means of competition that rely on creativity. Saudi architectural firms should realize that creativity needs to be enhanced and encouraged based on Saudi-specific architectural needs and demands. A better understanding of 
what makes Saudi Arabian designers more creative is definitely needed to facilitate creativity.

\section{Limitations and Directions for Future Research}

As in any research, the current study has some limitations. The major one is associated with the sample size which consisted of 210 professionals from five privately owned architectural firms in Saudi Arabia. Also, the sample size is considered too small to generalize the findings of this research. Moreover, the sample frame was limited to private firms which might practice creativity differently from government-owned firms in Saudi Arabia. Furthermore, the professional nature of our respondents and their highly creative work environment may limit generalizing the findings to less creative work environments. Finally, the use of cross-sectional data to test the posited hypotheses is considered another limitation to this study as cross-sectional studies may not provide definite conclusions about causality. These limitations, however, are less significant compared to the importance of the study and pose less of a threat to the validity of the results.

Our study offers interesting avenues for future research. Conducting studies on this topic in the future could extend the investigation of organizational creativity in architectural firms beyond the five private firms addressed here. Similar studies at other firms of various size and type in Saudi Arabia and other GCC countries could provide a benchmark for elevating creativity in architectural design firms in the GCC region. Additionally, selecting a larger sample size may be beneficial too. Furthermore, comparative studies between Saudi Arabia and Western countries like the US, Canada, and the UK that are already advanced in their organizational creativity standards, could help understand the gaps and look for improvements.

Amabile's componential theory addresses organizational creativity from the perspective of the work environment. However, other models such as Ekval's climatic and Woodman's interactionist models of creativity are also worth testing in the Saudi Arabia and GCC contexts. It should be noted that a significant amount of research has been conducted in fields other than architecture on individual creativity factors and motivators, which may, in conjunction with Amabile's model, provide a clear and comprehensive picture of what makes firms more creative and their individuals more innovative.

\section{Conclusion}

Motivating creativity is a complex process. Successful management of creativity should include management education about the types of motivation, their sources, their effects on performance, and their susceptibility to various work environment influences. 
It is clear that management should create a highly creative work environment by "loading up" the intrinsic and the extrinsic motivators in the work environment without paying attention to the type of extrinsic motivators and the context in which they are presented. Organizational leaders and managers should understand that human motivation at work is a complex process where it is possible to achieve synergy between individuals, their work environments, and types of motivators. Although the process is complex, it is also relevant since managers and executives are capable of nurturing creativity on a daily basis.

\section{REFERENCES}

Adams, R., Bessant, J, \& Phelps, R. (2006). Innovation management measurement: A review. International Journal of Management Reviews, 8(1), 21-47. http://dx.doi.org/10.1111/j.1468-2370.2006.00119.x

Amabile, T. M. (1983). The Social Psychology of Creativity. New York, NY: SpringerVerlag. http://dx.doi.org/10.1037/0022-3514.45.2.357

Amabile, T.M. (1988). A model of creativity and innovation in organizations. In: B.M. Staw \& L.L. Cummings (Eds.), Research in Organizational Behavior (pp. 123167). Greenwich: CT: JAI Press.

Amabile, T. M., \& Gryskiewicz, N.D. (1989). The creative environment scale: work environment inventory. Creativity Research Journal, 2(4), 231-252. http://dx.doi.org/10.1080/10400418909534321

Amabile, T. M., Conti, R., Coon, H., Lazenby, J., \& Herron, M. (1996). Assessing the Work Environment for Creativity. Academy of Management Journal, 39(5), 11541184. http://dx.doi.org/10.2307/256995

Amabile, T. M. (1998). How to kill creativity. Harvard Business Review, 76(5), 77-87. Amabile, T. M., Burnside, R., \& Gryskiewicz, S. S. (1999). User's Guide for KEYS: Assessing the Climate for Creativity. Center for Creative Leadership, Greensboro, NC.

Amabile, T. M., Hadley, C. N., \& Kramer, S. J. (2002). Creativity under the gun. Harvard Business Review, 80(8), 52-61.

Amabile, T. M., \& Kramer, S. J. (2007). Inner work life. Harvard Business Review, 85(5), 72-83.

Amabile, T. M., \& Mueller, J. S. (2008). Studying creativity, its processes, and its antecedents: An exploration of the componential theory of creativity. In J. Zhou \& C. E. Shalley (Eds.), Handbook of Organizational Creativity (pp. 33-64). New York: Lawrence Erlbaum Associates. 
Andriopoulos, C. (2001). Determinants of organizational creativity: a literature review. Management Decision, 39(10), 834-841.

Bessant, J., \& Tidd, J. (2007). Innovation and Entrepreneurship. John Wiley \& Sons.

Borghini, S. (2005). Organizational creativity: breaking equilibrium and order to innovate. Journal of Knowledge Management, 9(4), 19-33. http://dx.doi.org/10.1108/13673270510610305

Byrne, B. M. (2013). Structural Equation Modeling with AMOS: Basic Concepts, Applications, and Programming. Routledge.

Byron, K., Khazanchi, S., \& Nazarian, D. (2010). The relationship between stressors and creativity: a meta-analysis examining competing theoretical models. Journal of Applied Psychology, 95(1), 201-212. http://dx.doi.org/10.1037/a0017868

Carmines, E. G., \& Zeller, R. A. (1979). Reliability and validity assessment. Newbury Park, CA: Sage Publications. http://dx.doi.org/10.4135/9781412985642

Castro, F., Gomes, J., \& de Sousa, F. C. (2012). Do intelligent leaders make a difference? The effect of a leader's emotional intelligence on followers' creativity. Creativity and Innovation Management, 21(2), 171-182.

Chambers, J. A. (1969). Beginning a multidimensional theory of creativity. Psychological Reports, 25(3), 779-799. http://dx.doi.org/10.2466/pr0.1969.25.3.779

Coelho, F., Augusto, M., \& Lages, L. F. (2011). Contextual factors and the creativity of frontline employees: The mediating effects of role stress and intrinsic motivation. Journal of Retailing, 87(1), 31-45. http://dx.doi.org/10.1016/j.jretai.2010.11.004

Collins, M.A., \& Amabile, T.M. (1999). Motivation and creativity. In R.J. Sternberg (Ed.), Handbook of Creativity (pp. 297-312). Cambridge, U.K.: Cambridge University Press.

Coveney, B. (2008). Assessing the organizational climate for creativity in a UK Public Library Service: a case study. Library and Information Research, 32 (102), 38-56.

Cronbach, L. J., \& Meehl, P. E. (1955). Construct validity in psychological tests. Psychological Bulletin, 52(4), 281-302. http://dx.doi.org/10.1037/h0040957

Cronbach, L. J. (1971). Test validation. Educational Measurement, 2, 443-507.

Csikszentmihalyi, M. (1999). 16 Implications of a Systems Perspective for the Study of Creativity. Handbook of Creativity, 313.

Culpepper, M. K. (2010). KEYS to Creativity and Innovation: An Adopt-A-Measure Examination. The International Center for Studies in Creativity. Buffalo State College, US. 
De Jonge, J., Spoor, E., Sonnentag, S., Dormann, C., \& van den Tooren, M. (2012). "Take a break?!" Off-job recovery, job demands, and job resources as predictors of health, active learning, and creativity. European Journal of Work and Organizational Psychology, 21(3), 321-348.

Diliello, T. C., \& Houghton, J. D. (2008). Creative potential and practised creativity: Identifying untapped creativity in organizations. Creativity and Innovation Management, 17(1), 37-46. http://dx.doi.org/10.1111/j.1467-8691.2007.00464.x

Diliello, T. C., Houghton, J. D., \& Dawley, D. (2011). Narrowing the creativity gap: The moderating effects of perceived support for creativity. The Journal of Psychology, 145(3), 151-172. http://dx.doi.org/10.1080/00223980.2010.548412

Edmondson, A. (1999). Psychological Safety and Learning Behavior in Work Teams.

Administrative Science Quarterly, 44(2), 350-383.

http://dx.doi.org/10.2307/2666999

Eisenberger, R., Armeli, S., Rexwinkel, B., Lynch, P. D., \& Rhoades, L. (2001). Reciprocation of perceived organizational support. Journal of Applied Psychology, 86(1), 42-51. http://dx.doi.org/10.1037/0021-9010.86.1.42

Eisenberger, R., \& Shanock, L. (2009). Rewards, intrinsic motivation, and creativity: A case study of conceptual and methodological isolation. Creativity Research Journal, 15(2), 121-130. http://dx.doi.org/10.1080/10400419.2003.9651404

Epstein, R., Kaminaka, K., Phan, V. \& Uda, R. (2013). How is Creativity Best Managed? Some Empirical and Theoretical Guidelines. Creativity and Innovation Management, 22(4): 359-374

Fagerberg, J., Mowery, D. C., \& Nelson, R. R. (Eds.) (2006). The Oxford handbook of innovation. Oxford Handbooks Online. Retrieved from https://www.google.ae/books

Falk, R. F., \& Miller, N. B. (1992). A Primer for Soft Modeling. Akron, OH: University of Akron Press.

Farmer, S. M., Tierney, P., \& Kung-Mcintyre, K. (2003). Employee creativity in Taiwan: An application of role identity theory. Academy of Management Journal, 46(5), 618-630. http://dx.doi.org/10.2307/30040653

Fornell, C., \& Larcker, D. F. (1981). Structural equation models with unobservable variables and measurement error: algebra and statistics. Journal of Marketing Research, 18(3), 382-388. http://dx.doi.org/10.2307/3150980

Galende, J., \& de la Fuente, J. M. (2003). Internal factors determining a firm's innovative behaviour. Research Policy, 32(5), 715-736. 
Galenson, D. W. (2004). A portrait of the artist as a very young or very old innovator: Creativity at the extremes of the life cycle (Working Paper 10515). Retrieved from Nationl Bureau of Economic Research website: http://www.nber.org/papers/w10515

Gefen, D., \& Straub, D. W. (2000). The relative importance of perceived ease of use in IS adoption: a study of e-commerce adoption. Journal of the Association for Information Systems, 1(1), 8-23.

Gefen, D., Straub, D., \& Boudreau, M. C. (2000). Structural equation modeling and regression: Guidelines for research practice. Communications of the Association for Information Systems, 4(1), 7.

Gong, Y., Cheung, S. Y., Wang, M., \& Huang, J. C. (2012). Unfolding the proactive process for creativity: Integration of the employee proactively, information exchange, and psychological safety perspectives. Journal of Management, 38(5), 1611-1633. http://dx.doi.org/10.1177/0149206310380250

Haas, M. R. (2006). Knowledge gathering, team capabilities, and project performance in challenging work environments. Management Science,52(8), 1170-1184. http://dx.doi.org/10.1287/mnsc.1060.053

Haberland, G. S., \& Dacin, P. A. (1992). The development of a measure to assess viewers' judgments of the creativity of an advertisement: A preliminary study. Advances in consumer research, 19(1), 817-825.

Hamlin, R. G., \& Sawyer, J. (2007). Developing effective leadership behaviours: The value of evidence-based management. Business Leadership Review, 4(4), 1-16.

Hansen, D. J., Lumpkin, G. T., Hills, G. E. (2011). A multidimensional examination of a creativity-based opportunity recognition model. International Journal of Entrepreneurial Behavior \& Research, 17(5), 515-533. http://dx.doi.org/10.1108/135525511111588350

Hee Kim, K. (2006). Is creativity unidimensional or multidimensional? Analyses of the Torrance Tests of Creative Thinking. Creativity Research Journal, 18(3), 251-259. http://dx.doi.org/10.1207/s15326934crj1803_2

Hennessey, B. A., \& Amabile, T. M. (2010). Creativity. Annual Review of Psychology, 61, 569-598. http://dx.doi.org/10.1146/annurev.psych.093008.100416

Heye, D. (2006). Creativity and innovation: two key characteristics of the successful 21 st century information professional. Business Information Review, 23(4), 252256. http://dx.doi.org/10.1177/0266382106072255

Hunter, S.T., Bedell, K., E., \& Mumford, M. D. (2007). Climate for Creativity: A Quantitative Review. Creativity Research Journal, 19(1), 69-90. http://dx.doi.org/10.1080/10400410709336883 
Isaksen, S. G., Lauer, K. J., Ekvall, G., \& Britz, A. (2001). Perceptions of the best and worst climates for creativity: Preliminary validation evidence for the situational outlook questionnaire. Creativity Research Journal, 13(2), 171-184. http://dx.doi.org/10.1207/S15326934CRJ1302_5

Isaksen, S. G., \& Akkermans, H. J. (2011). Creative climate: A leadership lever for innovation. The Journal of Creative Behavior,45(3), 161-187. http://dx.doi.org/10.1002/j.2162-6057.2011.tb01425.x

Ismail, M. (2005). Creative climate and learning organization factors: their contribution towards innovation. Leadership \& Organization Development Journal, 26(8), 639654. http://dx.doi.org/10.1108/01437730510633719

Kurtzberg, T. R. (2005). Feeling creative, being creative: An empirical study of diversity and creativity in teams. Creativity Research Journal, 17(1), 51-65. http://dx.doi.org/10.1207/s15326934crj1701_5

Klijn, M., \& Tomic, W. (2010). A review of creativity within organizations from a psychological perspective. Journal of Management Development, 29(4), 322-343. http://dx.doi.org/10.1108/02621711011039141

Kozbelt, A., Beghetto, R. A., \& Runco, M. A. (2010). Theories of creativity. In J. C. Kaufman \& R. J. Sternberg (Eds.), Cambridge handbook of creativity (pp. 20-47). New York, NY: Cambridge University Press. http://dx.doi.org/10.1017/CBO9780511763205.004

Lin, C. Y. Y., \& Liu, F. C. (2012). A cross-level analysis of organizational creativity climate and perceived innovation: The mediating effect of work motivation. European Journal of Innovation Management, 15(1), 55-76.

Loewenberger, P. (2013). The Role of HRD in Stimulating, Supporting, and Sustaining Creativity and Innovation. Human Resource Development Review, 12(4), 422-455. http://dx.doi.org/10.1177/1534484313494088

Massaro, M., Bardy, R., \& Pitts, M. (2012). Supporting creativity through knowledge integration during the creative processes. A management control system perspective. Electronic Journal of Knowledge Management, 10(3), 258-267.

Mathisen, G. E., \& Einarsen, S. (2004). A review of instruments assessing creative and innovative environments within organizations. Creativity Research Journal, 16(1), 119-140. http://dx.doi.org/10.1207/s15326934crj1601_12

Meusburger, P. (2009). Milieus of creativity: The role of places, environments and spatial contexts. In Meusburger, P., Funke, J. \& Wunder, E. (Eds.), Milieus of creativity: An interdisciplinary approach to spatiality of creativity (pp. 97-153). Heidelberg, Germany: Springer. http://dx.doi.org/10.1007/978-1-4020-9877-2 
Mumford, M. D., Feldman, J. M., Hein, M. B., \& Nagao, D. J. (2001). Tradeoffs between ideas and structure: Individual versus group performance in creative problem solving. Journal of Creative Behavior, 35(1), 1-23. http://dx.doi.org/10.1002/j.2162-6057.2001.tb01218.x

Mumford, M. D., Waples, E. P., Antes, A. L., Brown, R. P., Connelly, S., Murphy, S. T., \& Devenport, L. D. (2010). Creativity and ethics: The relationship of creative and ethical problem-solving. Creativity Research Journal, 22(1), 74-89. http://dx.doi.org/10.1080/10400410903579619

Nielsen, B.D., Pickett, C.L. \& Simonton, D.K. (2008). Conceptual versus experimental creativity: Which works best on convergent and divergent thinking tasks?. Psychology of Aesthetics, Creativity, and the Arts, 2(3), 131-138. http://dx.doi.org/10.1037/1931-3896.2.3.131

Nunnally, J.C. „\& Bernstein, I. H. (1994). Psychometrictheory, (3rd ed.). NewYork, NY: McGraw-Hill.

Pablo, S., Campo, G., \& Skerlavaj, M. (2011). The organizational learning process as facilitator of innovation. International Journal of Innovation and Learning, 9(4), 401-421.

Perry-Smith, J., \& Shalley, C. (2003). The social side of creativity: A static and dynamic social network perspective. The Academy of Management Review, 28(1), 89-106.

Perry-Smith, J. E. (2014). Social network ties beyond nonredundancy: An experimental investigation of the effect of knowledge content and tie strength on creativity. Journal of Applied Psychology, 99(5), 831-846.

Pirola-Merlo, A., \& Mann, L. (2004). The relationship between individual creativity and team creativity: Aggregating across people and time. Journal of Organizational Behavior, 25(2), 235-257.

Pitta, D. A. (2009). Creating a culture of innovation at Portugal telecom. Journal of product $\quad \& \quad$ Brand $\quad$ Management, http://dx.doi.org/10.1108/10610420910989767

Rietzschel, E. F., De Dreu, C. K. W., \& Nijstad, B. A. (2009). What are we talking about, when we're talking about creativity? Group creativity as a multifaceted, multistage phenomenon. In Mannix, E. A., Neale, M. A., \& Goncalo, J. A. (Eds.), Research on Managing Groups and Teams: Creativity in Groups (Vol. 12, pp. 128). Bingley, UK: Emerald Press.

Runco, M. A. (2007). Correcting the Research on Creativity. Creativity Research Journal, 19(4), 321-327. 
Scharmer, C. O. (2009). Theory U: Learning from the Future as It Emerges. BerrettKoehler Publishers.

Shalley, C. E., \& Gilson, L. L. (2004). What leaders need to know: A review of social and contextual factors that can foster or hinder creativity. Leadership Quarterly, 15(1), 33-53. http://dx.doi.org/10.1016/j.leaqua.2003.12.004

Shalley, C., Zhou, J., \& Oldham, G. (2004). The effects of personal and contextual characteristics on creativity: Where should we go from here?. Journal of Management, 30(6), 933-958.

Shalley, C. E., Gilson, L. L., \& Blum, T. C. (2009). Interactive effects of growth need strength, work context, and job complexity on self-reported creative performance. Academy of Management Journal, 52(3), 489-505. http://dx.doi.org/10.5465/AMJ.2009.41330806

Spender, J.C., \& Strong, B. (2010, August 23). Employees hold the key to innovation. The Wall Street Journal, p. 11.

Stuhlfaut, M. W., \& Windels, K. (2012). Measuring the organisational impact on creativity: The creative code intensity scale. International Journal of Advertising, 31(4), 795-818. http://dx.doi.org/10.2501/IJA-31-4-795-818

Taggar, S. (2002). Individual creativity and group ability to utilize individual creative resources: a multilevel model. Academy of Management Journal, 45(2), 315-330. http://dx.doi.org/10.2307/3069349

Tierney, P., \& Farmer, S. M. (2011). Creative self-efficacy development and creative performance over time. Journal of Applied Psychology,96(2), 277-293. http://dx.doi.org/10.1037/a0020952

Tseng, H. M., \& Liu, F. C. (2011). Assessing the Climate for Creativity (KEYS): Confirmatory factor analysis and psychometric examination of a Taiwan version. International Journal of Assessment and Selection, 19(4), 438441. http://dx.doi.org/10.1111/j.1468-2389.2011.00572.x

Unsworth, C. (2001). Unpacking creativity. Academy of Management Review, 26(2), 286-297. http://dx.doi.org/10.2307/259123

Woodman, R. W., Sawyer, J. E., \& Griffin, R. W. (1993). Toward a theory of organizational creativity. Academy of Management Review, 18(2), 293-321. http://dx.doi.org/10.2307/258761

Yeh-Yun Lin, C., \& Liu, F. C. (2012). A cross-level analysis of organizational creativity climate and perceived innovation: The mediating effect of work motivation. European Journal of Innovation Management, 15(1), 55-76.

Yi, X., Hu, W., Plucker, J. A., \& McWilliams, J. (2013). Is there a developmental slump in creativity in China? The relationship between organizational climate and 
creativity development in Chinese adolescents. The Journal of Creative Behavior, 47(1), 22-40.

Zhou, J., Shalley, C. E., Martocchio, J. J., \& Ferris, G. R. (2003). Research on employee creativity: A critical review and directions for future research. Research in Personnel and Human Resources Management, 22, 165-217. http://dx.doi.org/10.1016/S0742-7301(03)22004-1

Zhou, J. (2008). New look at creativity in the entrepreneurial process. Strategic Entrepreneurship Journal, 2(1), 1-5. http://dx.doi.org/10.1002/sej.38

Zhou, Q., Hirst, G., \& Shipton, H. (2012). Promoting Creativity at Work: The Role of Problem-Solving Demand. Applied Psychology, 61(1), 56-80. http://dx.doi.org/10.1111/j.1464-0597.2011.00455.x 
